\title{
TRAIL- $\beta$ and TRAIL- $\gamma$ : two novel splice variants of the human TNF-related apoptosis-inducing ligand (TRAIL) without apoptotic potential
}

\author{
A Krieg ',4, T Krieg ', , M Wenzel', M Schmitt', U Ramp', B Fang ${ }^{3}$, HE Gabbert', CD Gerharz' and C Mahotka*,' \\ 'Institute of Pathology, Heinrich Heine-University, Moorenstr. 5, Duesseldorf D-40225, Germany; '2 Department of Gastroenterology, Hepatology and \\ Infectious Diseases, Heinrich Heine-University, Moorenstr. 5, Duesseldorf D-40225, Germany; ${ }^{3}$ Department of Thoracic and Cardiovascular Surgery, \\ University of Texas, MD Anderson Cancer Center, Houston, TX, USA
}

Tumour necrosis factor (TNF) related apoptosis-inducing ligand (TRAIL/APO2L) is a recently identified member of the TNF family, which induces programmed cell death in a variety of neoplastic cell types, but not in most nonneoplastic cells. In this study, we report on the identification of two novel alternative splice variants of TRAIL in neoplastic and non-neoplastic human cells lacking either exon 3 (TRAIL- $\beta$ ) or exons 2 and 3 (TRAIL- $\gamma$ ). In both splice variants, loss of exon 3 resulted in a frame shift generating a stop codon with consecutive extensive truncation in the extracellular domain. Ectopic expression revealed a loss of proapoptotic potential for both alternative splice variants. In contrast to the predominantly cytoplasmatic localisation of GFP-tagged TRAIL- $\alpha$ and TRAIL- $\beta$, TRAIL- $\gamma$ showed an additional association with the cell surface and nuclear membrane. In conclusion, alternative splicing might be involved in fine tuning of TRAlL-induced apoptosis and underlines the complexity of the TRAIL system.

British Journal of Cancer (2003) 88, 918 -927. doi:I0.1038/sj.bjc.6600772gg www.bjcancer.com

(C) 2003 Cancer Research UK

Keywords: alternative splicing; apoptosis; neoplastic cells; TRAIL

TRAIL/APO2L (tumour necrosis factor related apoptosis-inducing ligand or TRAIL- $\alpha$ ) is a recently identified type II transmembrane protein that belongs to the TNF family (Wiley et al, 1995; Pitti et al, 1996) and is processed proteolytically at the cell surface to form a soluble ligand (Mariani and Krammer, 1998). In contrast to other members of the TNF family, such as CD95L/FasL and TNF, TRAIL has been detected in a wide variety of both non-neoplastic and neoplastic cell types and tissues (Wiley et al, 1995; Pitti et al, 1996) and was found to induce programmed cell death in cancer cells, but not in most normal cells (Gura, 1997; Sheridan et al, 1997; Walczak et al, 1997; Ashkenazi et al, 1999; Dejosez et al, 2000). Consistently, TRAIL was shown to suppress growth of human tumours transplanted into mice (Walczak et al, 1999) and to improve survival of the tumour-bearing animals (Ashkenazi et al, 1999). Although repeated intravenous injections of TRAIL in primates did not cause detectable toxicity to non-neoplastic tissues (Ashkenazi et al, 1999), in vitro susceptibility to TRAIL-mediated apoptosis was reported recently for human hepatocytes (Jo et al, 2000).

Induction of apoptosis by TRAIL seems to be more complex than apoptosis mediated by other members of the TNF family, because four different TRAIL-binding receptors have been identified so far (Griffith and Lynch, 1998; Degli-Esposti, 1999). TRAIL-R1/DR4 and TRAIL-R2/DR5/KILLER/TRICK2 exhibit a death domain in their cytoplasmatic regions and signal apoptotic cell death upon overexpression (Gura, 1997; Pan et al, 1997a, b;

*Correspondence: C Mahotka; E-mail: mahotka@uni-duesseldorf.de

${ }^{4}$ Contributed equally to this work.

Revised 4 November 2002; accepted 25 November 2003
Sheridan et al, 1997). In contrast, ectopic overexpression of TRAIL-R3/DcR1/TRID, which lacks a cytoplasmatic region (DegliEsposti et al, 1997b; MacFarlane et al, 1997; Pan et al, 1997a; Sheridan et al, 1997; Mongkolsapaya et al, 1998), and TRAIL-R4/ DcR2/TRUNDD, which exhibits only a truncated intracellular death domain (Degli-Esposti et al, 1997a; Marsters et al, 1997; Kischkel et al, 2000), rather protects cells from TRAIL-induced apoptosis (Degli-Esposti et al, 1997a; Pan et al, 1997a; Kischkel et al, 2000). Although the molecular pathways of TRAIL-induced programmed cell death are still under investigation, recent studies have demonstrated the recruitment of FADD and DAP3 as adaptors in the death-inducing signalling complex (DISC) and activation of caspase-8 (Bodmer et al, 2000a; Kischkel et al, 2000; Kuang et al, 2000; Sprick et al, 2000; Miyazaki and Reed, 2001).

Several studies found a correlation between TRAIL resistance and expression levels of TRAIL in human cancer cell lines and keratinocytes (Rieger et al, 1999; Zhang et al, 1999; Dejosez et al, 2000). Moreover, the presence of intracellular caspase-8 (Eggert et $a l, 2001$ ) and antiapoptotic proteins such as c-FLIP (Griffith et al, 1998; Leverkus et al, 2000) and/or activation of the transcription factor NF- $\kappa \mathrm{B}$ seem to determine TRAIL sensitivity (Jeremias et al, 1998; Goke et al, 2000; Keane et al, 2000; Bernard et al, 2001; Franco et al, 2001; Oya et al, 2001; Wuchter et al, 2001).

Transcriptional modification by alternative splicing is known to be involved in the regulation of apoptotic cell death in mammalian cells as well (Jiang and $\mathrm{Wu}, 1999)$. Thus, several apoptosis-related genes have been identified, for example, murine CD95L (Ayroldi et al, 1999), CD95 (Cascino et al, 1995), caspase-2, -8, -9 (Jiang et al, 1998; Srinivasula et al, 1999; Cote et al, 2001; Eckhart et al, 2001), cFLIP (Scaffidi et al, 1999) and survivin (Mahotka et al, 1999; Conway et al, 2000; Krieg et al, 2002), which are alternatively 
processed and thereby may exert distinct regulatory functions in the fine tuning of apoptosis.

In this report, we describe the identification of two novel TRAIL splice variants, i.e., TRAIL- $\beta$ and TRAIL- $\gamma$, in non-neoplastic and neoplastic cells. The lack of exon 3 in TRAIL- $\beta$ and of exons 2 and 3 in TRAIL- $\gamma$ results in massive truncation of the extracellular binding domain and loss of proapoptotic potential.

\section{MATERIALS AND METHODS}

\section{Cell lines and cultures}

All RCC cell lines $(n=30)$ used in this study were derived from typical representatives of the clear cell, chromophilic/papillary and chromophobe types of RCC, established in our laboratory as previously described (Gerharz et al, 1999). The cell lines were maintained with Dulbecco's modified Eagle's medium (DMEM, Gibco, Karlsruhe, Germany) supplemented with $10 \%$ fetal calf serum, penicillin and streptomycin. PBMCs were cultivated in RPMI medium (Gibco, Karlsruhe, Germany) supplemented with $10 \%$ fetal calf serum, penicillin and streptomycin. All cell lines and PBMCs were cultured at $37^{\circ} \mathrm{C}$ in an atmosphere with $5 \% \mathrm{CO}_{2}$.

\section{Stimulation of PBMCs}

Buffy coats of blood samples from four healthy independent donors were collected according to standard procedures. For stimulation, cells were seeded at a density of $5 \times 10^{5} \mathrm{cells} \mathrm{ml}^{-1}$ and treated with $10 \mu \mathrm{g} \mathrm{ml}^{-1}$ concanavalin A (Sigma-Aldrich, Deisenhofen, Germany). Stimulated PBMCs were collected for RNA extraction after emergence of cell blasts (2-4 days).

\section{RNA extraction}

Total RNA was isolated from the cultured RCC cell lines, PBMCs, mouse tissues and the mouse tumour cell line RAW 264.7 using the RNeasy kit (Qiagen, Hilden, Germany). The integrity of RNA (28S/ $18 \mathrm{~S}$ ribosomal RNA) was controlled by electrophoresis followed by staining with ethidium bromide.

\section{Reverse transcription (RT) and PCR amplification of TRAIL}

For cDNA synthesis, $2 \mu \mathrm{g}$ of total RNA was reversely transcribed in a final volume of $30 \mu \mathrm{l}$ containing $25 \mu \mathrm{M}$ of each dNTP (Stratagene, Heidelberg, Germany), 100 pmol random hexamer primer (Stratagene), $20 \mathrm{U}$ of recombinant RNasin RNase inhibitor (Promega, Heidelberg, Germany) as well as 5 U of AMV reverse transcriptase (Promega) with the corresponding RT buffer. The RT reactions were incubated at $55^{\circ} \mathrm{C}$ for $1 \mathrm{~h}$.

PCR amplification of human TRAIL and GAPDH was performed in a final volume of $50 \mu \mathrm{l}$ containing $3 \mu \mathrm{l}$ first-strand cDNA solution, $2.5 \mathrm{U}$ of Taq polymerase, $1 \times$ PCR buffer, $25 \mu \mathrm{M}$ of each dNTP (Qiagen, Hilden, Germany) and 25 pmol of each $3^{\prime}$ and $5^{\prime}$ TRAIL-specific oligonucleotide (forward primer, $5^{\prime}$-GAA TCC CAT GGC TAT GAT GGA GGT CCA G- $3^{\prime}$ and reverse primer, $5^{\prime}$-GGA TTC GAG GAC CTC TTT CTC TCA CTA-3') (GenBank accession number U37518) or $3^{\prime}$ and $5^{\prime}$ GAPDH-specific oligonucleotide (forward primer, 5'-ACG GAT TTG GTC GTA TTG GGC G-3' and reverse primer, $5^{\prime}$-CTC CTG GAA GAT GGT GAT GG- $3^{\prime}$ ) (GenBank accession number J04038). Conditions of PCR were as follows: initial denaturation step at $94{ }^{\circ} \mathrm{C}$ for $2 \mathrm{~min}$, followed by 35 cycles (TRAIL) or 27 cycles (GAPDH) of denaturation for $30 \mathrm{~s}$, annealing for $1 \mathrm{~min}$ at $58^{\circ} \mathrm{C}$ (TRAIL) or $64^{\circ} \mathrm{C}$ (GAPDH), extension at $72^{\circ} \mathrm{C}$ for $1 \mathrm{~min}$ and a final extension step at $72^{\circ} \mathrm{C}$ for $5 \mathrm{~min}$. PCR products were electrophoresed on $3 \%$ agarose gels containing ethidium bromide and visualised under UV transillumination.
Real-time PCR of murine TRAIL was performed on the LightCycler $^{(\mathbb{R}}$ (Roche Diagnostics, Mannheim, Germany). Amplification was performed in a total volume of $20 \mu \mathrm{l}$ in the presence of $2 \mu \mathrm{l} 10 \times$ SYBR Green Fast Start Reaction Mix (Roche Diagnostics), $3 \mathrm{mM} \mathrm{MgCl}_{2}, 25$ pmol of each $3^{\prime}$ and $5^{\prime}$ TRAIL-specific oligonucleotide (forward primer, $5^{\prime}$-GAA TCC CTG CAT TGG GAA GTC AGA$3^{\prime}$ and reverse primer, $5^{\prime}$-GGA TCC TTA ATT AAA AAG GCT CCA AAG AAG-3') (GenBank accession number U37522) and $2 \mu \mathrm{l}$ of cDNA (or water as negative control). Real-time PCR was carried out in glass capillaries with an initial denaturation step of $10 \mathrm{~min}$ at $95^{\circ} \mathrm{C}$, followed by 65 cycles of $0 \mathrm{~s}$ at $95^{\circ} \mathrm{C}, 4 \mathrm{~s}$ annealing at $72^{\circ} \mathrm{C}$, and elongation for $36 \mathrm{~s}$ at $72^{\circ} \mathrm{C}$. Melting curve was directly performed after amplification with an initial denaturation of $0 \mathrm{~s}$ at $95^{\circ} \mathrm{C}$, a temperature delay at $82^{\circ} \mathrm{C}$ for $30 \mathrm{~s}$ and a continous heating on $95^{\circ} \mathrm{C}$ for $0 \mathrm{~s}$ with a slope of $0.1^{\circ} \mathrm{Cs}^{-1}$. To confirm the results, PCR products were electrophoresed on $3 \%$ agarose gels containing ethidium bromide and visualised under UV transillumination.

\section{Sequence analysis}

Bands of interest were excised from agarose gels and isolated using the QIAquick gel extraction kit (Qiagen), ligated into the pGEM-Tcloning vector (Promega) and cloned in accordance to standard protocols. Plasmid DNA was recovered employing the Plasmid Mini Kit (Qiagen), cycle sequenced using T7 or SP6 site-specific primers, and analysed with an ABI Prism 310 sequencing apparatus (Applied Biosystems, Weiterstadt, Germany).

\section{Cloning of TRAIL coding sequences}

To generate GFP-tagged constructs of TRAIL variants, the coding cDNA sequences of the three TRAIL variants were amplified by PCR as described above. PCR amplification products were cloned into the pGEM-T-vector as described above, digested with EcoRI and BamHI, ligated into the mammalian expression vector pEGFPC1 (Clontech, Heidelberg, Germany) and cloned according to standard protocols. GFP-TRAIL- $\alpha$ construct was cloned as recently described (Kagawa et al, 2001).

Transfection of cultured cells, assessment of cell viability and apoptosis as well as analysis of subcellular localisation by confocal laser scanning microscopy

Subconfluent TRAIL-sensitive HeLa cells were transiently transfected in 24-wells using polyfect transfection reagent, as described by the manufacturer (Qiagen). HeLa cells were incubated with the DNA and the transfection reagent for $24 \mathrm{~h}$. To determine the number of cells that underwent apoptosis, HeLa cells were seeded on coverslips in 24-well plates, cultivated for $24 \mathrm{~h}$ and transfected as described above. After transfection, cells were washed twice with sterile PBS and fixed for $10 \mathrm{~min}$ in ice-cold methanol. Cells were treated with DAPI staining solution $\left(0.1 \mu \mathrm{g} \mathrm{ml}^{-1}\right)$ for $5 \mathrm{~min}$ and washed twice with PBS. Up to 300 cells were counted in five different fields per preparation using an Axioscop fluorescence microscope (Zeiss, Germany). The percentage of apoptotic cells was calculated as the ratio between the number of GFP-positive cells with fragmented nuclei and all GFP-positive cells. The data presented are the mean \pm s.d. from three replicates.

Cell number was analysed using the colorimetric MTT assay as described before (Mosman, 1983) and measured on a spectrophotometric Titertek Multiskan plate reader (Labsystems, Finland) at $570 \mathrm{~nm}$. The percentage of viable cells in each well was calculated as the ratio between the absorbance of TRAIL- $\alpha$-, TRAIL- $\beta$ - or TRAIL- $\gamma$-transfected cells and the absorbance of vector control-transfected cells. The data presented are the mean \pm s.d. from six replicates.

Statistical significance was considered for $P$-values of Student's $t$-test less than 0.05 . Transfection efficiency was directly 
A
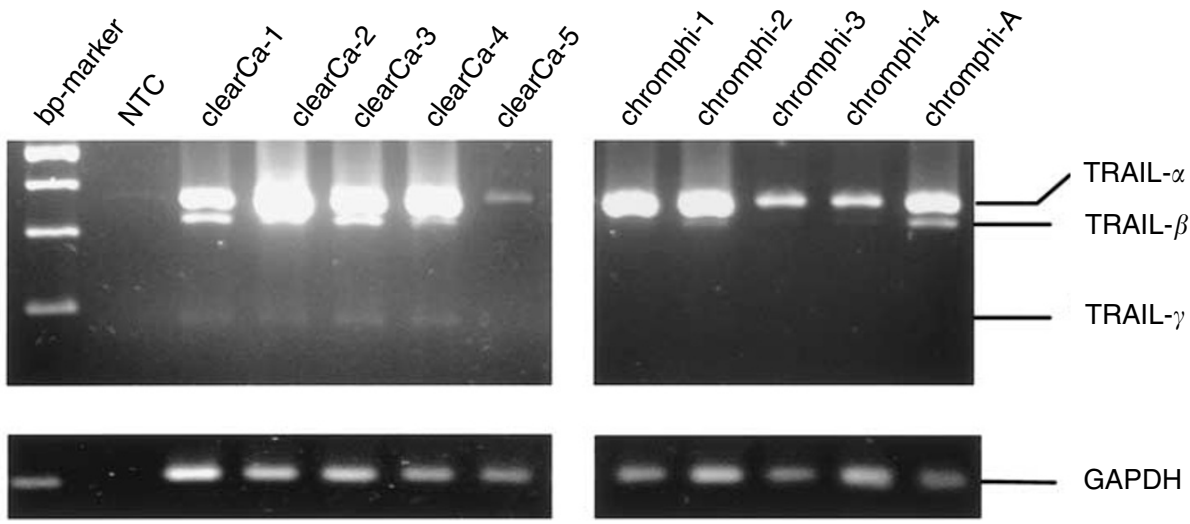

GAPDH

B
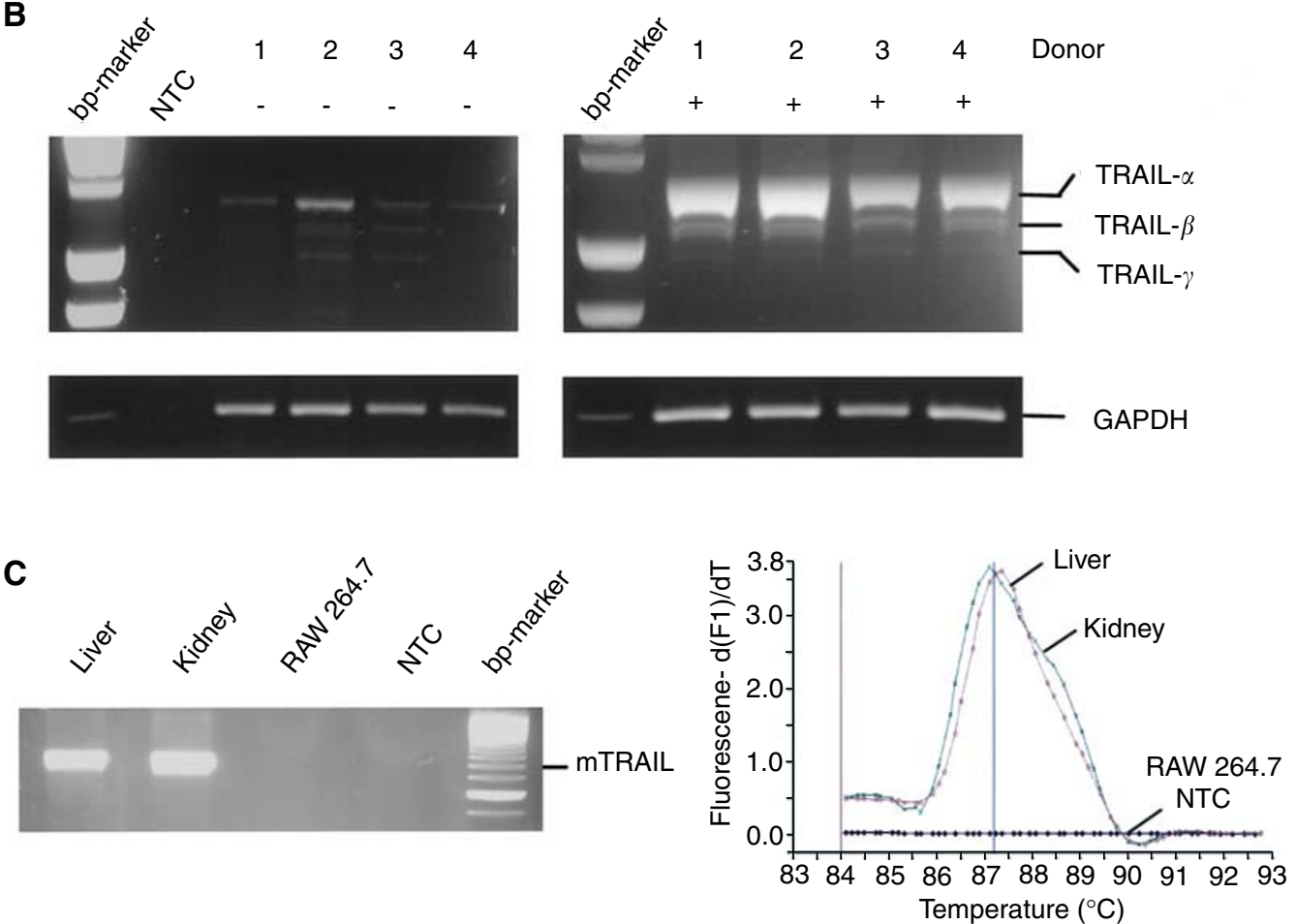

Figure I Expression of different TRAIL mRNA variants in neoplastic and non-neoplastic human cells. (A) TRAIL- $\alpha$ is the dominant transcript in renal cell carcinoma cell lines, whereas TRAIL- $\beta$ and $-\gamma$ show low expression levels only. Of note, expression of TRAIL- $\gamma$ was not observed in chromophilic/papillary (chromphi-I to -4) and chromophobe (chrompho-A) RCCs. (B) The alternative splice variants TRAIL- $\beta$ and TRAIL- $\gamma$ are expressed at low levels in both unstimulated $(-)$ and concanavalin A-stimulated (+) PBMCs. (C) No alternative TRAlL splice variants could be detected in mouse liver and kidney or in the mouse tumour cell line RAW 264.7. Melting curve analysis showed a distinct peak for full-length TRAIL in liver and kidney tissue, but no additional signals for splice variants.

determined by the ratio of GFP-positive and -negative cells. The transfection efficiencies varied between 20 and $30 \%$ for HeLa cells.

To analyse the subcellular localisation of TRAIL-variants, HEK293 cells in the exponential growth phase were seeded onto sterile coverslips in six-well plates at a density of $1 \times 10^{5}$ cells well $^{-1}$. After $24 \mathrm{~h}$, cells were transfected as described above. Afterwards, cells were washed two times in PBS, fixed in ice-cold methanol for $10 \mathrm{~min}$ and incubated with endoplasmatic reticulum-specific fluorescence dye concanavalin A Alexa-564 (Molecular Probes, Eugene, USA) $\left(25 \mu \mathrm{g} \mathrm{ml}^{-1}\right)$ for $30 \mathrm{~min}$. Coverslips were washed again in PBS, mounted and examined using a confocal laser scanning system TCS-NT (Leica, Bensheim, Germany).

\section{Western blot analysis}

Protein extracts from transiently transfected HeLa cells were isolated by disrupting cells in lysis buffer $(100 \mathrm{mM} \mathrm{NaCl}, 10 \mathrm{mM}$ Tris- $\mathrm{HCl} \mathrm{pH}$ 7.6, $1 \mathrm{~mm}$ EDTA $\mathrm{pH} 8$ and protease inhibitor). Protein samples (up to $50 \mu \mathrm{g}$ ) were electrophoresed in $12 \%$ SDSpolyacrylamide gels at $70 \mathrm{~mA}$ for $4 \mathrm{~h}$. Blotting to Opitran BA-S85 nitrocellulose membranes (Schleicher \& Schuell, Dassel, Germany) was performed for up to $2 \mathrm{~h}$ at $650 \mathrm{~mA}$ in a tank of transfer buffer pH 8.3 (25 mM Tris- $\mathrm{HCl}, 1925 \mathrm{~mm}$ glycine, 20\% methanol) using the Hoefer TE series Transphor electrophoresis unit (Hoefer Scientific Intsruments, San Fransisco, USA). To verify transfer efficiency and protein integrity, nitrocellulose membranes were 


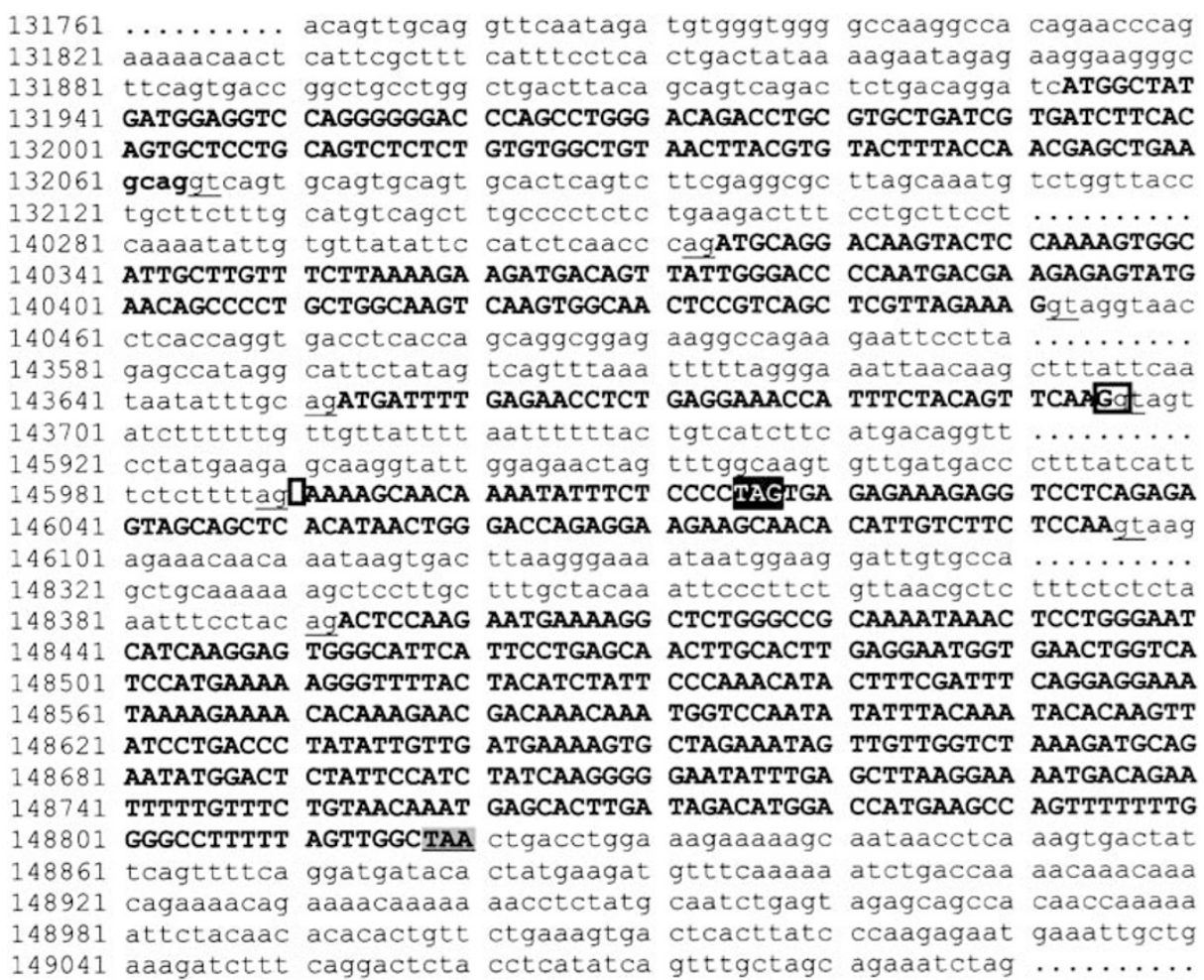

Figure 2 Genomic organisation of the human TRAIL gene. The cDNA sequence of human TRAlL (accession no. U375 I 8) is marked in bold letters within the Homo sapiens chromosome 3, clone hRPK.44 A I (accession no. AC00705I). SD and SA sites at the exon-intron boundaries are underlined. Of note, differences between our analysis of the genomic organisation and a recent publication (Gong and Almasan, 2000) are marked by squares. The stop codon generated by alternative splicing of exons 2 and 3 is marked by a black-shaded square.

stained with Ponceau S $0.2 \%$. Afterwards, membranes were blocked in blocking buffer (100 mM Tris- $\mathrm{HCl}, \mathrm{pH} 7.5,150 \mathrm{~mm}$ $\mathrm{NaCl}, 0.2 \%$ Tween 20 ) plus $3 \%$ nonfat dry milk and $1 \%$ BSA for $2 \mathrm{~h}$ at room temperature. Immunodetection of GFP-TRAIL-fusion proteins was carried out by incubating membranes with a $1: 2000$ dilution of monoclonal mouse anti-GFP antibody JL-8 (Clontech, Palo Alto, USA) overnight at $4{ }^{\circ} \mathrm{C}$. PARP cleavage was detected by incubating membranes with a $1: 500$ dilution of monoclonal mouse anti- human PARP antibody, clone AC10.5 (Pharmingen, San Diego, USA) overnight at $4^{\circ} \mathrm{C}$. Subsequently, membranes were incubated with a 1:1000 dilution with horseradish-peroxidase linked anti-mouse antibody (Amersham Pharmacia, Freiburg, Germany) for $1.5 \mathrm{~h}$.

Proteins were detected by incubation with Lumi-Light substrate (Roche, Mannheim, Germany). Equal loading was confirmed by $\beta$ actin detection with a mouse anti- $\beta$-actin-specific antibody, clone AC-15 (Sigma-Aldrich, Taufeirchren, Germany). Data on X-ray films were quantified by densitometry with the program Tina 20 (raytest Isotopenmessgeräte $\mathrm{GmbH}$, Germany).

\section{RESULTS}

\section{Identification of two novel TRAIL splice variants}

As revealed by RT-PCR analysis, all RCC cell lines $(n=30)$ expressed TRAIL- $\alpha$, irrespective of their histological types (Figure 1A). Besides the expected amplification product of $371 \mathrm{bp}$, however, two additional bands of 328 and $190 \mathrm{bp}$ were coamplified. These three amplification products were sequenced. The largest band was identified as regularly spliced TRAIL- $\alpha$, whereas the $328 \mathrm{bp}$ product was identified as a TRAIL variant with a deletion of 43 nucleotides corresponding to nucleotides $358-400$ of the TRAIL- $\alpha$ cDNA of the human TRAIL sequence (GenBank Accession no. U37518). The smallest PCR product (190 bp) lacked nucleotides $220-357$.

Although the genomic organisation and the exon-intron boundaries of TRAIL had recently been published (Gong and Almasan, 2000), we repeated the database analysis by running advanced BLAST, looking for a genomic clone that contains parts of the human TRAIL gene. This database search revealed that the Homo sapiens Chromosome 3-clone hRPK.44 A (Accession no. AC007051) contained the entire coding sequence of TRAIL. Subsequently, we determined the exon-intron organisation of the human TRAIL gene, which consists of five exons (Figure 2). Of note, we observed a difference in two nucleotides (position 143697 and 145990) marked by squares in Figure 2 when compared to the published sequence (Gong and Almasan, 2000). According to the genomic organisation, the 43 nucleotides deleted in the $328 \mathrm{bp}$ long amplification product corresponded to exon 3 and, therefore, we designated this new alternative splice variant as TRAIL- $\beta$. The smaller band ( $190 \mathrm{bp})$ was found to lack both exon 2 (138 nucleotides) and exon 3 and, therefore, was designated as TRAIL- $\gamma$. Additional amplification of genomic DNA by PCR showed no product and excluded the presence of pseudogenes.

To investigate whether the novel TRAIL splice variants are exclusively generated in neoplastic cells, we performed RT-PCR with unstimulated and stimulated PBMCs showing that the alternative splice variants TRAIL- $\beta$ and TRAIL- $\gamma$ are expressed in non-neoplastic cells as well (Figure 1B). No alternative TRAIL splice variants, however, could be detected in mouse liver and kidney or in the mouse tumour cell line RAW 264.7 (Figure 1C). This observation strongly suggests that alternative splicing of TRAIL may be a species-restricted phenomenon. 
$\mathbf{A}$

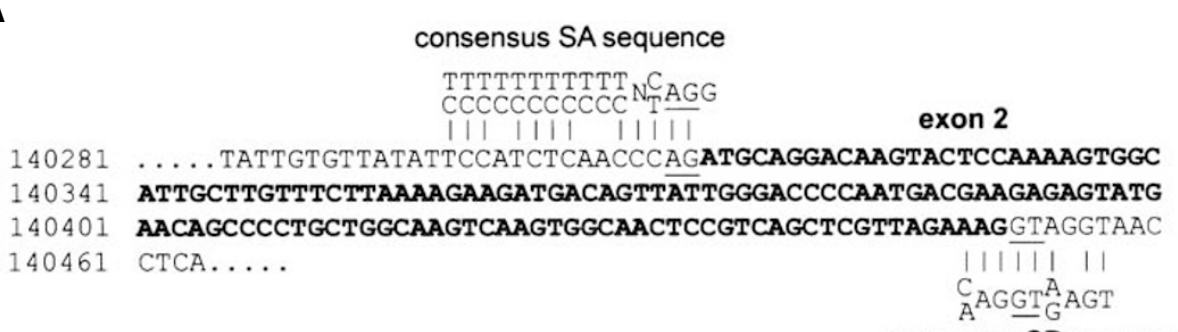

consensus SD sequence

consensus SA sequence

TTTTTTTT $\mathrm{C}_{\text {TAGG }}$

$\operatorname{CCCCCCC} T^{\mathrm{T}}$

exon 3

143636 ...AATAATATTTGCAGATGATTTTGAGAACCTCTGAGGAAACCATTTCTACAGTTCAAGGTAGT . . .

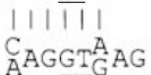

consensus SD sequence

B

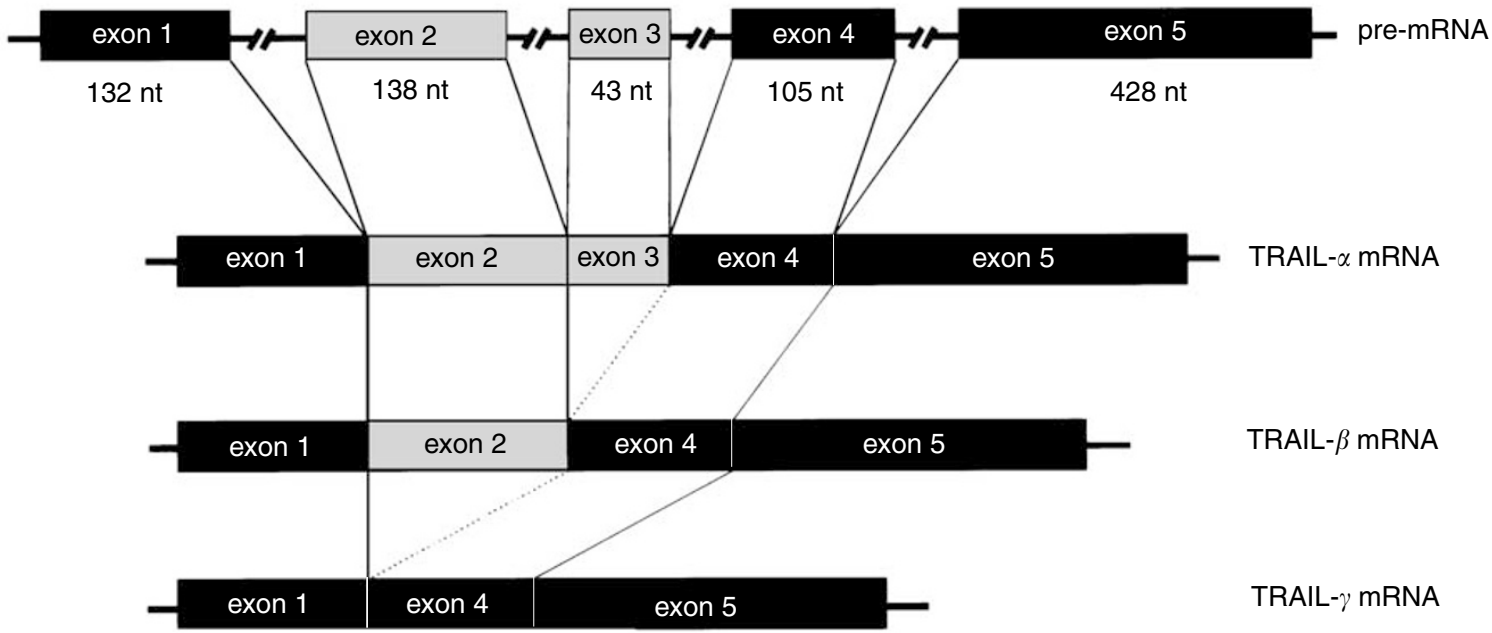

Figure 3 SD and SA sites flanking exons 2 and $3(\mathbf{A})$ and the resulting TRAIL mRNAs (B).

Splice donor and acceptor sites at the intron-exon and exon-intron boundaries of exons 2 and 3 are suitable for alternative splicing

Computational analysis with the Signal program (PC/GENE package) showed that exon 2 as well as exon 3 are flanked by splice donor (SD) and splice acceptor (SA) sites matching to the consensus sequence of common SD sites ( $\{\mathrm{C} / \mathrm{A}\} \mathrm{AG} \mid \mathrm{GT}\{\mathrm{A} / \mathrm{G}\} \mathrm{AGT})$ and SA sites $\left(\{\mathrm{T} / \mathrm{C}\}_{11} \mathrm{~N}\{\mathrm{C} / \mathrm{T}\} \mathrm{AG} \mid \mathrm{G}\right)$ as shown in Figure $3 \mathrm{~A}$. Both the SA sites at position $140298-140457$ of exon 2 and at position $143641-143700$ of exon 3 contain the AG bases of SA sites as well as the GT bases of the SD sites that are necessary for posttranscriptional splicing on intron-exon boundaries. The necessary GT bases of SD sites for splicing processes exist also at the exonintron boundaries of exons 2 and 3. Taken together, these data indicate that post-transcriptional processing of the TRAIL-premRNA leads to the generation of three alternative splice products, i.e., TRAIL- $\alpha$, TRAIL- $\beta$ and TRAIL- $\gamma$ (Figure 3B).
Alterations of protein domains in the novel TRAIL isoforms and functional implications

Computational analysis of TRAIL- $\alpha$ and its novel alternative splice variants showed that loss of exon 3 resulted in a frame shift generating a stop codon with consecutive truncation in the extracellular domains of both TRAIL- $\beta$ and $-\gamma$. This truncation resulted in a 98 amino-acids long TRAIL- $\beta$ and a 52 amino-acids long TRAIL- $\gamma$ (Figure 4A). Moreover, PSORT II analysis (Nakai and Horton, 1999) identified KIFL, a KKXX-like motif known as endoplasmatic reticulum membrane retention signal at the $\mathrm{C}$ terminus of both TRAIL- $\beta$ and $-\gamma$. PROSITE scan (Bairoch, 1991) also identified potential protein kinase $C$ phosphorylation sites between amino acids $92-94$ of TRAIL- $\beta$ and amino acids $46-48$ of TRAIL- $\gamma$, immediately adjacent to the potential endoplasmatic membrane retention signal. TRAIL- $\beta$ also contains a potential cAMP- and cGMP-dependent protein kinase phosphorylation site between amino acids 89- and 92 (Figure 4B). 
A

TRAIL $-\gamma$

TRAIL- $\beta$

TRAIL $-\alpha$

TRAIL $-\gamma$

TRAIL- $\beta$

TRAIL $-\alpha$

TRAIL $-\gamma$

TRAIL $-\beta$

TRAIL $-\alpha$

TRAIL $-\gamma$

TRAIL $-\beta$

TRAIL $-\alpha$

TRAIL $-\gamma$

TRAIL- $\beta$

TRAIL $-\alpha$

B

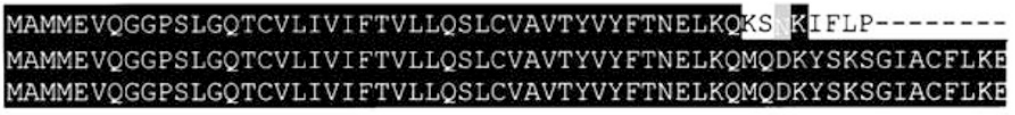

DDSYWDPNDEESMNSPCWQVKWQLRQLVR



121 RVAAHITGTRGRSNTLSSPNSKNEKALGRKINSWESSRSGHS FLSNLHLRNGELVIHEKG

181 FYYIYSQTYFRFQEEIKENTKNDKQMVQYIYKYTSYPDPILLMKSARNSCWSKDAEYGLY

TRAIL- $\alpha, 281$ aa

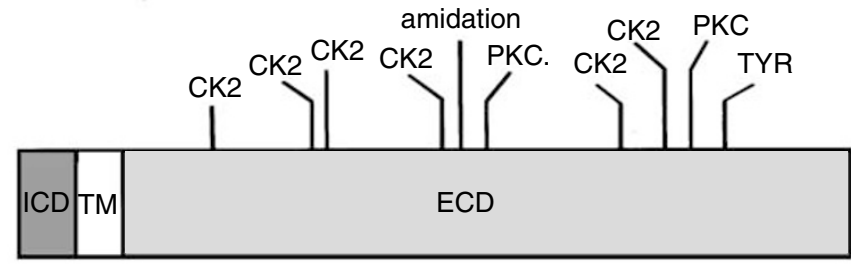

TRAIL- $\beta, 98$ aa

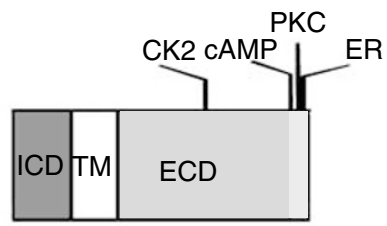

TRAIL- $\gamma, 52$ aa

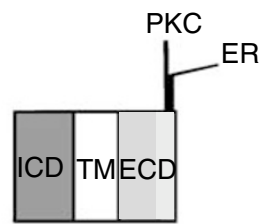

Figure 4 Structural alterations of protein domains in the novel TRAIL isoforms. (A) Multiple alignment of the three TRAIL isoforms was performed by Clustal W (Thompson et al, 1994) and enhanced with Boxshade. Dark shading: residues are highly conserved; light shading: residues are less well conserved; not shaded: residues are not conserved. (B) Protein sequences were analysed by PROSITE scan. Potential domains and modification sites are marked. A frame shift because of alternative splicing results in a potential endoplasmatic reticulum membrane retention (ER) signal at the C-terminus adjacent to new potential PKC-phoshorylation sites in both TRAIL- $\beta$ and $-\gamma$. Light grey box $=$ newly generated ER-signal containing domain. ICD $=$ intracellular domain; $\mathrm{ECD}=$ extracellular domain; $\mathrm{TM}=$ transmembrane region; $\mathrm{ER}=$ endoplasmatic reticulum membrane retention signal; $\mathrm{CAMP}=\mathrm{cAMP}$-dependent protein kinase phoshorylation site; CK2 = casein kinase II phosphorylation site; TYR = tyrosine kinase phosphorylation site; PKC $=$ protein kinase $\mathrm{C}$ phosphorylation site.

Although PROSITE scan analysis had identified a potential ER membrane retention signal at the C-terminus of both TRAIL- $\beta$ and $-\gamma$, PSORT II analysis predicted a preferential cytoplasmatic localisation for all TRAIL isoforms (data not shown). To further investigate the subcellular localisation of TRAIL- $\alpha$ and its alternative splice variants, GFP-fused TRAIL variants were ectopically overexpressed in HEK293 cells. Using concanavalin A Alexa-594 as a marker of endoplasmatic reticulum, confocal laser microscopy did not reveal a selective accumulation of TRAIL- $\beta$ or
TRAIL- $\gamma$ in the endoplasmatic reticulum (Figure 5). However, TRAIL- $\gamma$ was found to produce a more intensive fluorescence of the cell surface and nuclear membrane when compared to the other splice variants.

Using HeLa cells known to be sensitive to TRAIL-mediated apoptosis (Harper et al, 2001), ectopic expression of TRAIL variants revealed marked differences in the apoptotic activity of TRAIL- $\alpha$ and its novel alternative splice variants: ectopic expression of TRAIL- $\alpha$ led to huge clusters of apoptotic cells, which were 
not observed after transfection with the other TRAIL variants or the vector control (Figure 5B). DAPI staining permitted the identification of fragmented or condensed nuclei indicative for apoptosis (Figure 5C) and permitted a visual quantification of apoptosis (see Material and Methods). Using this assay, a significant decrease of apoptotic cells was observed after ectopic expression of GFP-TRAIL- $\beta$ or GFP-TRAIL- $\gamma$ or the vector control when compared to GFP-TRAIL- $\alpha$-transfected HeLa cells (Figure 5D). The decrease of apoptotic potential observed for GFP-TRAIL- $\beta$ and GFP-TRAIL- $\gamma$ was paralleled by a significant increase of cell viability as demonstrated by MTT assays (Figure 5E). To further confirm the effects of the different TRAIL variants on apoptosis, PARP cleavage was analysed by a monoclonal mouse antibody, that recognises a $85 \mathrm{kDa}$ cleavage product besides the $116 \mathrm{kDa}$ uncleaved PARP. PARP cleavage was found to be enhanced three-fold by ectopic expression of TRAIL- $\alpha$ in comparison with the other TRAIL variants or the vector control (Figure 5F).

To ensure that the observed effects were based on protein expression of all TRAIL variants, the expression of the fusion
A
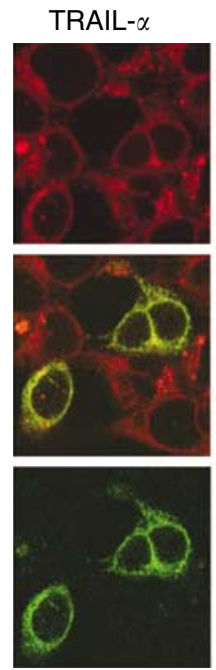

B
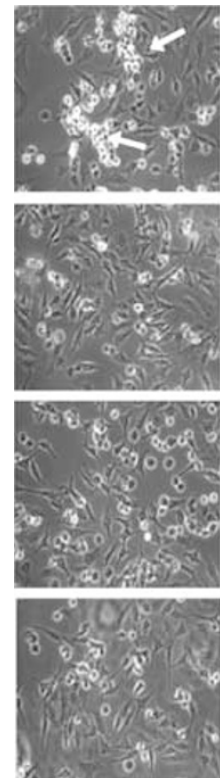

TRAIL- $\beta$
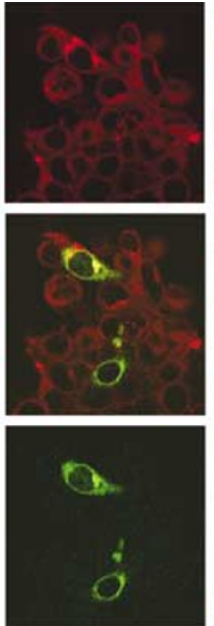

GFP/DAPI
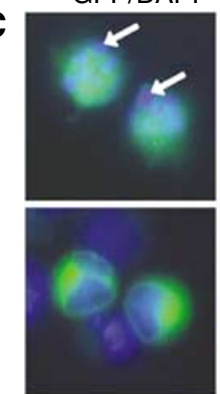

GFP-TRAIL- $\beta$

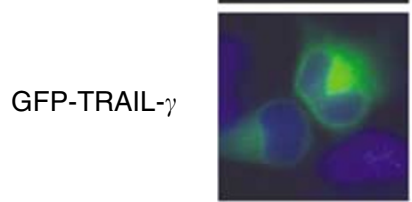

Vector control

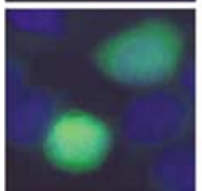

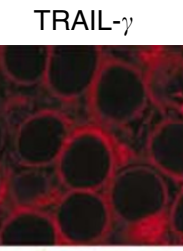

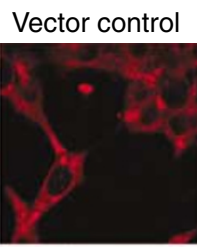

Concanavalin A

Alexa-594
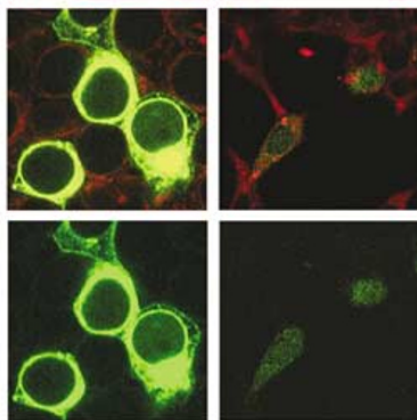

TRAIL variants

(+ vector control)
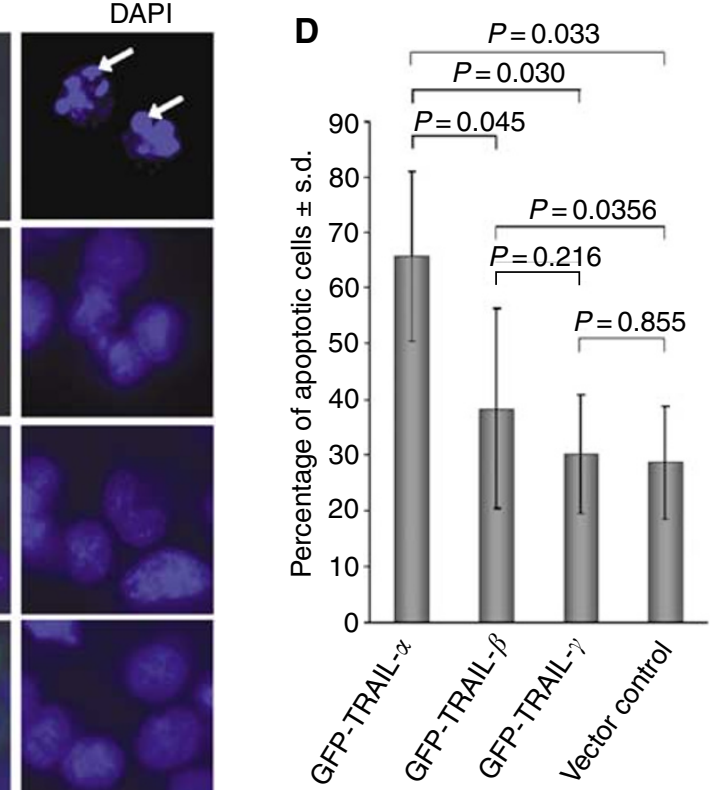

Figure 5 A-D Differential subcellular localisation and lost proapoptotic potential of the novel TRAIL variants. (A) Confocal laser scanning microscopy revealed a prominent cytoplasmatic localisation of all GFP-tagged TRAIL variants. The endoplasmatic reticulum was marked with the endoplasmatic reticulum-specific fluorescence dye concanavalin A Alexa-594. Yellow staining in 'merge' indicates colocalisation of all GFP-tagged TRAIL variants and the endoplasmatic reticulum. Of note, GFP-tagged TRAIL- $\gamma$ additionally showed a prominent fluorescence of both the cell surface and the nuclear membrane, which was not observed for the other TRAIL variants. HeLa cells known to be sensitive to TRAlL-mediated apoptosis (Harper et al, 200 I) were transfected with GFP constructs containing the different TRAIL isoforms or the empty vector. (B) Phase contrast microscopy of the transfected cells showed prominent clusters of apoptotic cells (arrows) in cultures of GFP- TRAIL- $\alpha$ transfected cells but not after transfection of other TRAIL variants or the vector control. (C) DAPI staining of nuclei permitted an identification of nuclei with fragmented or condensed chromatin, indicative for apoptotic cells (arrows), which could easily be distinguished from cells with intact nuclei under UV light. (D) Visual quantification of apoptosis was done by counting all GFP-positive cells as well as all GFP-positive cells with fragmented/condensed nuclei. The percentage of apoptotic cells was calculated as the ratio between the number of GFP-positive cells with fragmented or condensed nuclei and all GFP-positive cells. (Continued on next page.) 
$\mathbf{E}$

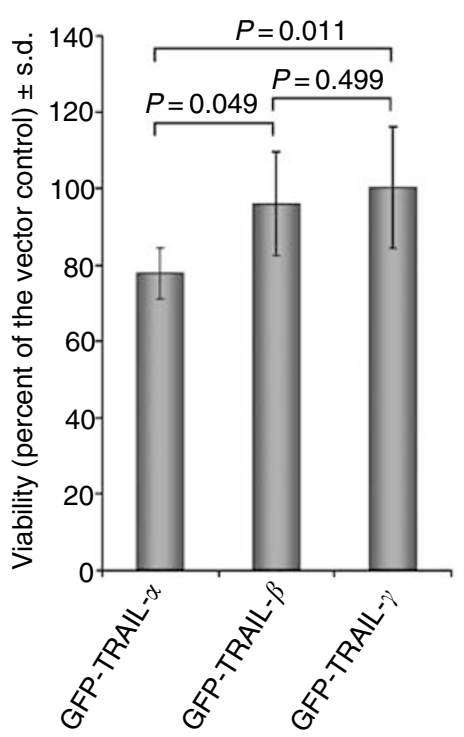

$\mathbf{F}$

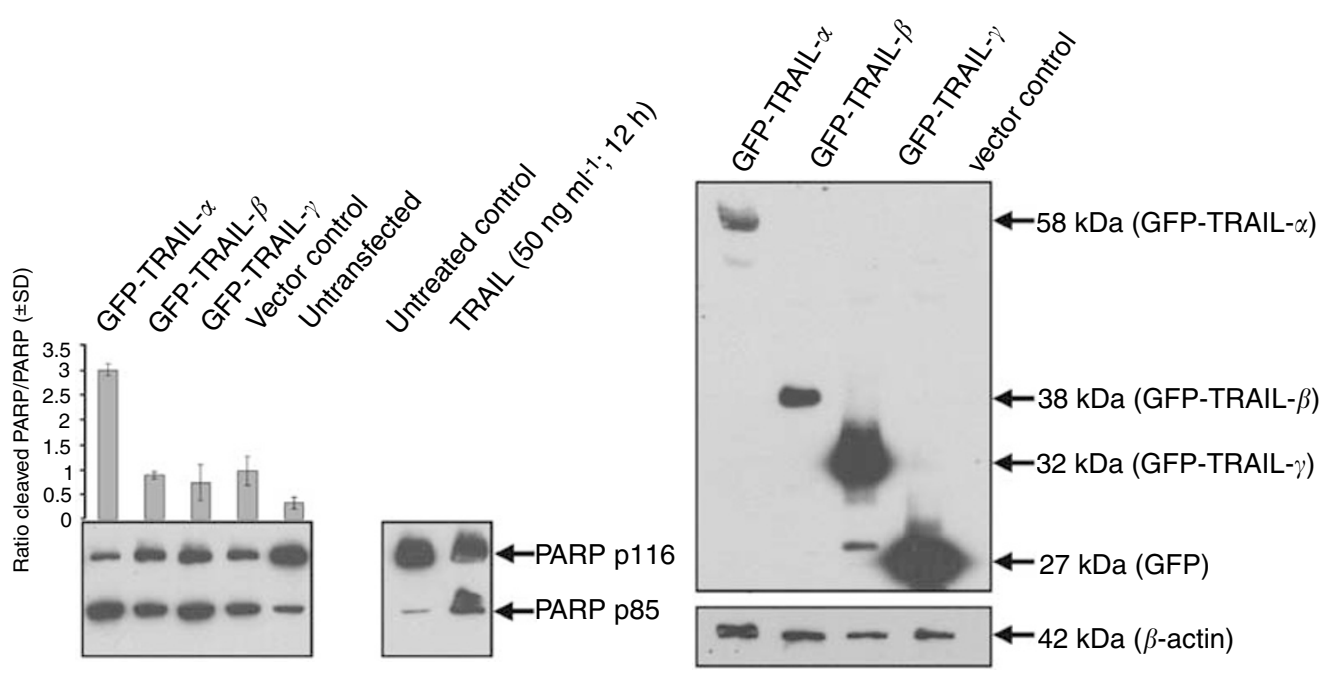

G

Figure 5 Continued E-G This visual apoptosis assay $(n=3)$ further confimed the loss of proapoptotic potential for GFP-TRAIL- $\beta$ and GFP-TRAIL- $\gamma$, which also became evident $(\mathbf{E})$ from an increase of surviving cells in our MTT assays $(n=6)$. (F) Immunodetection of the caspase-3-dependent 'death substrate' PARP showed enhancend cleavage only after ectopic expression of GFP-TRAIL- $\alpha$. To ensure the detection of this cleavage product, protein lysates from TRAIL-treated control cells were separated on the same gel. The data presented are the mean \pm s.d. from three independent transfections. (G) To show that the recombinant TRAIL variants are expressed on protein level, whole protein lysates of transfected HeLa cells were separated by SDS gels and immunodetection of GFP fusion proteins with anti-GFP-IgG was carried out after blotting on nitrocellulose membrane.

proteins was confirmed by Western blot analysis using a mononoclonal mouse anti-GFP anbtibody (Figure 5G).

\section{DISCUSSION}

In this study, we report on the identification of two novel splice variants of TRAIL, i.e., TRAIL- $\beta$ and TRAIL- $\gamma$, in RCC cell lines of all major histological subtypes. These previously unknown splice variants were not clearly detectable in RNase protection assays (Dejosez et al, 2000), because only $43 \mathrm{bp}$ (TRAIL- $\beta$ ) or $181 \mathrm{bp}$ (TRAIL- $\gamma$ ) differences in length were found in comparison with the primarily identified TRAIL- $\alpha$ transcript (Wiley et al, 1995; Pitti et al, 1996). It was especially intriguing to detect these splice variants in non-neoplastic human cells as well, whereas no corresponding splice variants were found in different cell types of murine origin.

Alternative splicing permits a high degree of protein diversity generating structurally and functionally distinct proteins that differ in their subcellular localisation, molecular targets or stability. Splice variants have previously been found to play a key role in the regulation of apoptosis as well, determining the actions of many apoptosis-related genes at all levels of apoptotic signalling pathways (Jiang and $\mathrm{Wu}, 1999$ ). Thus, the CD95 (APO-1, Fas) receptor exists in membrane-bound and soluble isoforms which antagonistically affect apoptosis (Jiang and $\mathrm{Wu}, 1999$ ). The Bcl-2 family encompasses genes, for example, Bcl-X and its different splice variants $\mathrm{Bcl}-\mathrm{X}_{\mathrm{L}} / \mathrm{X}_{\mathrm{S}}$, which antagonistically determine the susceptibility to cell death signals (Boise et al, 1993). Finally, different isoforms of caspases (Srinivasula et al, 1999; Cote et al, 2001; Eckhart et al, 2001) and inhibitor of apoptosis (IAP) proteins (Mahotka et al, 1999; Conway et al, 2000) are generated by alternative splicing. The novel TRAIL isoforms described in this study show an extensive loss of their extracellular binding domain, which plays a key role for trimeric stability, ligand-receptor binding capacity and apoptotic signalling (Pitti et al, 1996; Sheridan et al, 1997; Griffith and Lynch, 1998; Ashkenazi et al, 1999; Bodmer et al, 2000b; Kagawa et al, 2001). Consequently, the novel truncated TRAIL isoforms should be unable to form stabile dimeric or trimeric receptor-ligand complexes and fail to trigger TRAIL mediated-apoptosis as demonstrated by our transfection experiments.

At first sight, therefore, TRAIL- $\beta$ and TRAIL- $\gamma$ may interfere with the fine tuning of TRAIL actions simply by reducing the amount of full-length ligand. In fact, the generation of truncated isoforms has been suggested as an additional mechanism to quantitatively regulate gene expression and action, because the mRNAs of all isoforms originate from the same pre-mRNA precursor pool (Jiang and $\mathrm{Wu}, 1999$ ). Interestingly in this context, however, ectopically overexpressed TRAIL- $\gamma$ exhibited a more prominent association with the cell surface and the nuclear membrane when compared to both TRAIL- $\alpha$ and TRAIL- $\beta$. Further experimental work, therefore, will have to show whether these alternative splice variants actually play a passive regulatory role for TRAIL-mediated apoptosis only or acquired novel functional properties as well. In any case, the identification of two novel splice variants may have implications for our understanding of TRAILmediated apoptosis in neoplastic and non-neoplastic human cells.

\section{ACKNOWLEDGEMENTS}

We thank Sigrid Khalil, Michael Ringler and Martina Bellack for technical assistance. The results of this work are part of the $\mathrm{PhD}$ thesis of Thomas Krieg and the MD thesis of Andreas Krieg. This work was supported by a grant from the Deutsche Forschungsgemeinschaft and by the Stiftung für Altersforschung. 


\section{REFERENCES}

Ashkenazi A, Pai RC, Fong S, Leung S, Lawrence DA, Marsters SA, Blackie C, Chang L, McMurtrey AE, Hebert A, DeForge L, Koumenis IL, Lewis D, Harris L, Bussiere J, Koeppen H, Shahrokh Z, Schwall RH (1999) Safety and antitumor activity of recombinant soluble Apo2 ligand. J Clin Invest 104: $155-162$

Ayroldi E, D’Adamio F, Zollo O, Agostini M, Moraca R, Cannarile L, Migliorati G, Delfino DV, Riccardi C (1999) Cloning and expression of a short Fas ligand: a new alternatively spliced product of the mouse Fas ligand gene. Blood 94: 3456-3467

Bairoch A (1991) PROSITE: a dictionary of sites and patterns in proteins. Nucleic Acids Res 19: $2241-2245$

Bernard D, Quatannens B, Vandenbunder B, Abbadie C (2001) Rel/NFkappaB transcription factors protect against tumor necrosis factor (TNF)-related apoptosis-inducing ligand (TRAIL)-induced apoptosis by up-regulating the TRAIL decoy receptor DcR1. J Biol Chem 276: $27322-$ 27328

Bodmer JL, Holler N, Reynard S, Vinciguerra P, Schneider P, Juo P, Blenis J, Tschopp J (2000a) TRAIL receptor-2 signals apoptosis through FADD and caspase-8. Nat Cell Biol 2: $241-243$

Bodmer JL, Meier P, Tschopp J, Schneider P (2000b) Cysteine 230 is essential for the structure and activity of the cytotoxic ligand TRAIL. $J$ Biol Chem 275: $20632-20637$

Boise LH, Gonzalez-Garcia M, Postema CE, Ding L, Lindsten T, Turka LA, Mao X, Nunez G, Thompson CB. (1993) Bcl-x, a bcl-related gene that functions as a dominant regulator of apoptotic cell death. Cell 74: $597-608$

Cascino I, Fiucci G, Papoff G, Ruberti G (1995) Three functional soluble forms of the human apoptosis-inducing Fas molecule are produced by alternative splicing. J Immunol 154: 2706-2713

Conway EM, Pollefeyt S, Cornelissen J, DeBaere I, Steiner-Mosonyi M, Ong K, Baens M, Collen D, Schuh AC (2000) Three differentially expressed survivin cDNA variants encode proteins with distinct antiapoptotic functions. Blood 95: 1435-1442

Cote J, Dupuis S, Jiang Z, Wu JY (2001) Caspase-2 pre-mRNA alternative splicing: identification of an intronic element containing a decoy $3^{\prime}$ acceptor site. Proc Natl Acad Sci USA 98: $938-943$

Degli-Esposti MA (1999) To die or not to die-the quest of the TRAIL receptors. J Leuk Biol 65: 535-542

Degli-Esposti MA, Dougall WC, Smolak PJ, Waugh JY, Smith CA, Goodwin RG (1997a) The novel receptor TRAIL-R4 induces NF- $\kappa B$ and protects against TRAIL-mediated apoptosis, yet retains an incomplete death domain. Immunity 7: 813-820

Degli-Esposti MA, Smolak PJ, Walczak H, Waugh J, Huang CP, DuBose R, Goodwin RG, Smith CA (1997b) Cloning and characterization of TRAIL R3, a novel member of the emerging TRAIL receptor family. J Exp Med 186: $1165-1170$

Dejosez M, Ramp U, Mahotka C, Krieg A, Walczak H, Gabbert HE, Gerharz CD (2000) Sensitivity to TRAIL/APO-2L-mediated apoptosis in human renal cell carcinomas and its enhancement by topotecan. Cell Death Differ 7: $1127-1136$

Eckhart L, Henry M, Santos-Beneit AM, Schmitz I, Krueger A, Fischer H, Bach J, Ban J, Kirchhoff S, Krammer PH, Mollinedo F, Tschachler E. (2001) Alternative splicing of caspase-8 mRNA during differentiation of human leukocytes. Biochem Biophys Res Commun 289: 777-781

Eggert A, Grotzer MA, Zuzak TJ, Wiewrodt BR, Ho R, Ikegaki N, Brodeur GM (2001) Resistance to tumor necrosis factor related apoptosis-inducing ligand-induced apoptosis in neuroblastoma cells correlates with a loss of caspase-8 expression. Cancer Res 61: $1314-1319$

Franco AV, Zhang XD, Van Berkel E, Sanders JE, Zhang XY, Thomas WD, Nguyen T, Hersey P (2001) The role of NF-kappa B in TNF-related apoptosis-inducing ligand (TRAIL)-induced apoptosis of melanoma cells. J Immunol 166: 5337 - 5345

Gerharz CD, Ramp U, Dejosez M, Mahotka C, Czarnotta B, Bretschneider U, Lorenz I, Müller M, Krammer PH, Gabbert HE (1999) Resisance to CD95 (APO-1/Fas)-mediated apoptosis in human renal cell carcinomas: an important factor for evasion from negative growth control. Lab Invest 79: $1521-1534$

Goke R, Goke A, Goke B, Chen Y (2000) Regulation of TRAIL-induced apoptosis by transcription factors. Cell Immunol 201: 77-82

Gong B, Almasan A (2000) Genomic organization and transcriptional regulation of human Apo2/TRAIL gene. Biochem Biophys Res Commun 278: $747-752$
Griffith TS, Chin WA, Jackson GC, Lynch DH, Kubin MZ (1998) Intracellular regulation of TRAIL-induced apoptosis in human melanoma cells. J Immunol 161: $2833-2840$

Griffith TS, Lynch DH (1998) TRAIL: a molecule with multiple receptors and control mechanisms. Curr Opin Immunol 10: 559-563

Gura T (1997) How TRAIL kills cancer cells but not normal cells. Science 277: 68

Harper N, Farrow SN, Kaptein A, Cohen GM, MacFarlane M (2001) Modulation of tumor necrosis factor apoptosis-inducing ligand-induced $\mathrm{NF}-\kappa \mathrm{B}$ activation by inhibition of apical caspases. J Biol Chem 276: $34743-34752$

Jeremias I, Kupatt C, Baumann B, Herr I, Wirth T, Debatin KM (1998) Inhibition of nuclear factor kappaB activation attenuates apoptosis resistance in lymphoid cells. Blood 91: 4624-4631

Jiang ZH, Wu JY (1999) Alternative splicing and programmed cell death. Proc Soc Exp Biol Med 220: 64-72

Jiang ZH, Zhang WJ, Rao Y, Wu JY (1998) Regulation of Ich-1 pre-mRNA alternative splicing and apoptosis by mammalian splicing factors. Proc Natl Acad Sci USA 95: 9155-9160

Jo M, Kim TH, Seol DW, Esplen JE, Dorko K, Billiar TR, Strom SC (2000) Apoptosis induced in normal human hepatocytes by tumor necrosis factor-related apoptosis-inducing ligand. Nat Med 6: 564-567

Kagawa S, He C, Gu J, Koch P, Rha SJ, Roth JA, Curley SA, Stephens LC Fang B (2001) Antitumor activity and bystander effects of the tumor necrosis factor-related apoptosis-inducing ligand (TRAIL) gene. Cancer Res 61: $3330-3338$

Keane MM, Rubinstein Y, Cuello M, Ettenberg SA, Banerjee P, Nau MM, Lipkowitz S (2000) Inhibition of NF-kappaB activity enhances TRAIL mediated apoptosis in breast cancer cell lines. Breast Cancer Res Treat 64: $211-219$

Kischkel FC, Lawrence DA, Chuntharapai A, Schow P, Kim KJ, Ashkenazi A (2000) Apo2L/TRAIL-dependent recruitment of endogenous FADD and caspase-8 to death receptors 4 and 5. Immunity 12: 611-620

Krieg A, Mahotka C, Krieg T, Grabsch H, Müller W, Takeno S, Suschek CV, Heydthausen M, Gabbert HE, Gerharz CD (2002) Expression of different survivin variants in gastric carcinomas: first clues to a role of survivin-2B in tumor progression. Br J Cancer 86: 737-743

Kuang AA, Diehl GE, Zhang J, Winoto A (2000) FADD is required for DR4- and DR5-mediated apoptosis: lack of trail-induced apoptosis in FADD-deficient mouse embryonic fibroblasts. J Biol Chem 275: $25065-25068$

Leverkus M, Neumann M, Mengling T, Rauch CT, Brocker EB, Krammer PH, Walczak H (2000) Regulation of tumor necrosis factor-related apoptosis-inducing ligand sensitivity in primary and transformed human keratinocytes. Cancer Res 60: 553-559

MacFarlane M, Ahmad M, Srinivasula SM, Fernandes-Alnemri T, Cohen GM, Alnemri ES (1997) Identification and molecular cloning of two novel receptors for the cytotoxic ligand TRAIL. J Immunol 272: 25417-25420

Mahotka C, Wenzel M, Springer E, Gabbert HE, Gerharz CD (1999) Survivin- $\triangle \mathrm{Ex} 3$ and Survivin-2B: two novel splice variants of the apoptosis inhibitor survivin with different anti-apoptotic properties. Cancer Res 59: 6097-6102

Mariani SM, Krammer PH (1998) Surface expression of TRAIL/Apo-2 ligand in activated mouse T and B cells. Eur J Immunol 28: $1492-1498$

Marsters SA, Sheridan JP, Pitti RM, Huang A, Skubatch M, Baldwin D, Yuan J, Gurney A, Goddard AD, Godowski P, Ashkenazi A (1997) A novel receptor for Apo2L/TRAIL contains a truncated death domain. Curr Biol 7: $1003-1006$

Miyazaki T, Reed JC (2001) A GTP-binding adapter protein couples TRAIL receptors to apoptosis-inducing proteins. Nat Immunol 2: 493-500

Mongkolsapaya J, Cowper AE, Xu XN, Morris G, McMichael AJ, Bell JI, Screaton GR (1998) Lymphocyte inhibitor of TRAIL (TNF-related apoptosis-inducing ligand): a new receptor protecting lymphocytes from the death ligand TRAIL. J Immunol 160: 3-6

Mosman T (1983) Rapid colorimetric assay for cellular growth and survival: application to proliferation and cytotoxity assays. J Immunol Methods 65: $55-64$

Nakai K, Horton P (1999) PSORT: a program for detecting sorting signals in proteins and predicting their subcellular localization. Trends Biochem Sci 24: $34-36$

Oya M, Ohtsubo M, Takayanagi A, Tachibana M, Shimizu N, Murai M (2001) Constitutive activation of nuclear factor-kappaB prevents TRAILinduced apoptosis in renal cancer cells. Oncogene 20: 3888-3896 
Pan G, Ni J, Wie YF, Yu G, Gentz R, Dixit VM (1997a) An antagonist decoy receptor and a death domain-containing receptor for TRAIL. Science 277: $815-818$

Pan G, O’Rourke K, Chinnaiyan AM, Gentz R, Ebner R, Ni J, Dixit VM (1997b) The receptor for the cytotoxic ligand TRAIL. Science 276: 111 113

Pitti RM, Marsters SA, Ruppert S, Donahue CJ, Moore A, Ashkenazi A (1996) Induction of apoptosis by Apo-2 ligand, a new member of the tumor necrosis factor cytokine family. J Biol Chem 271: 12687-12690

Rieger J, Ohgaki H, Kleihues P, Weller M (1999) Human astrocytic brain tumors express AP02L/TRAIL. Acta Neuropathol (Berl) 97: 1-4

Scaffidi C, Schmitz I, Krammer PH, Peter ME (1999) The role of c-FLIP in modulation of CD95-induced apoptosis. J Biol Chem 274: $1541-1548$

Sheridan JP, Marsters SA, Pitti RM, Gurney A, Skubatch M, Baldwin D, Ramakrishnan L, Gray CL, Baker K, Wood WI, Goddard AD, Godowski P, Ashkenazi A (1997) Control of TRAIL-induced apoptosis by a family of signaling and decoy receptors. Science 277: 818-821

Sprick MR, Weigand MA, Rieser E, Rauch CT, Juo P, Blenis J, Krammer PH, Walczak H (2000) FADD/MORT1 and caspase-8 are recruited to TRAIL receptors 1 and 2 and are essential for apoptosis mediated by TRAIL receptor 2. Immunity 12: 599-609

Srinivasula SM, Ahmad M, Guo Y, Zhan Y, Lazebnik Y, Fernandes-Alnemri T, Alnemri ES (1999) Identification of an endogenous dominant-negative short isoform of caspase-9 that can regulate apoptosis. Cancer Res 59: $999-1002$
Thompson JD, Higgins DG, Gibson TJ (1994) CLUSTAL W: improving the sensitivity of progressive multiple sequence alignment through sequence weighting, positions-specific gap penalties and weight matrix choice. Nucleic Acids Res 22: $4673-4680$

Walczak H, Degli-Esposti MA, Johnson RS, Smolak PJ, Waugh JY, Boiani N, Timour MS, Gerhart MJ, Schooley KA, Smith CA, Goodwin RG, Rauch CT (1997) TRAIL-R2: a novel apoptosis-mediating receptor for TRAIL. EMBO J 16: 5386 - 5397

Walczak H, Miller RE, Ariail K, Gliniak B, Griffith TS, Kubin M, Chin W, Jones J, Woodward A, Le T, Smith C, Smolak P, Goodwin RG, Rauch CT, Schuh JC, Lynch DH (1999) Tumoricidal activity of Tumor necrosis factor-related apoptosis-inducing ligand in vivo. Nat Med 5: $157-163$

Wiley SR, Schooley K, Smolak PJ, Din WS, Huang CP, Nicholl JK, Sutherland GR, Smith TD, Rauch C, Smith CA (1995) Identification and characterization of a new member of the TNF family that induces apoptosis. Immunity 3: 673-682

Wuchter C, Krappmann D, Cai Z, Ruppert V, Scheidereit C, Dorken B, Ludwig WD, Karawajew L (2001) In vitro susceptibility to TRAILinduced apoptosis of acute leukemia cells in the context of TRAIL receptor gene expression and constitutive NF-kappa B activity. Leukemia 15: $921-928$

Zhang XD, Franco A, Myers K, Gray C, Nguyen T, Hersey P (1999) Relation of TNF-related apoptosis-inducing ligand (TRAIL) receptor and FLICEinhibitory protein expression to TRAIL-induced apoptosis of melanoma. Cancer Res 59: $2747-2753$ 